CALIFORNIA STATE UNIVERSITY, NORTHRIDGE

\title{
MULLER-LYER ILLUSION IN HYPERACTIVE BOYS
}

A thegis submitted in partial satisfaction of the requirements for

the degree of Master of Arts in

$$
\text { Psychology }
$$

by

Robert Roy Houghton 
The thesis of Robert RQy Houghton is approved:

\section{Committee Chasperson}

California State University, Northridge

May, 1976 


\section{ACKNOWLEDGMENT}

I wish to thank Drs. Frank Dudenhoeffer, Jim Holroyd, Skip Bazer and staff, in particular, Jane Peart, Nancy Peart, and Sue Swanson; Dr. R. Vendell Coffelt and staff, in particular, Patti Martinez, Martan Noreland, Joan Harmon, and Lisa Coffelt for their consideration and their dedication to children with special needs; the members of my thesis committee, Barbara Tabachnick, Alice HawkinsNotestine, and Phil Swith for their assistance and understanding; and, especially, the children for their enthusiasm and zind indulzence. 


\section{TABLE OF CONTENTS}

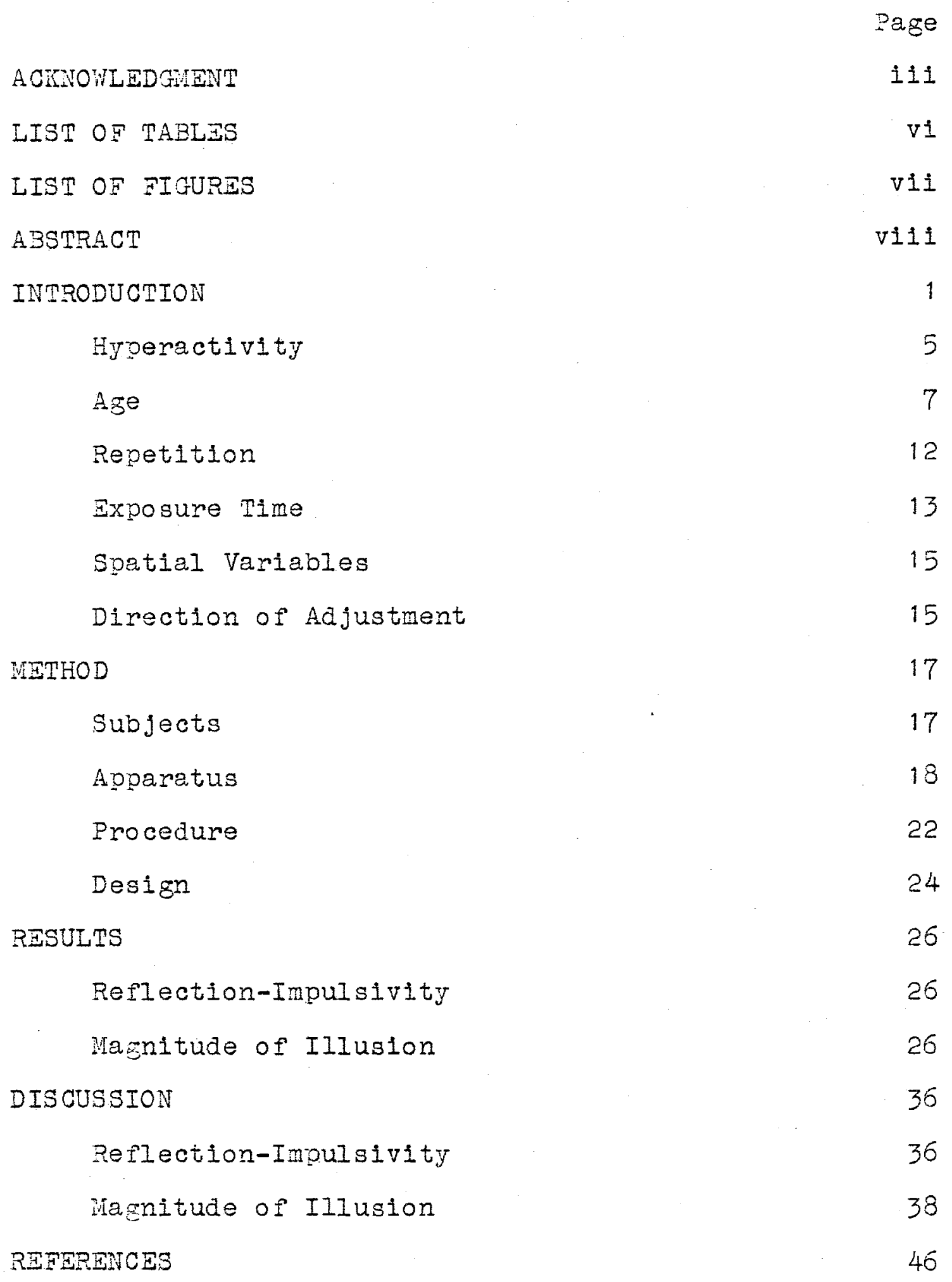


A. Physician and Medication Information

for the Hyperactives

B. Sample Item from Matching Tamillar Figures 50

c. Directions for Matching Familiar Figures 51

D. Instructions for Muller-Lyer 52 


\section{LIST OI TABLES}

Table

Page

1. Analysis of Variance for Effects of Population and Age on Response Time to the Matching Familiar Figures Test

2. Analysis of Variance for Iffects of Population, Age, Repetition, and Direction on Magnitude of Illusion

3. Newman-Keuls Comparisons between Illusion for Direction by $310 \mathrm{cks}$ of Repetition

4. Newman-Keuls Comparisons between Illusion for Non-Iyperactives by Age

5. Tests for Aze Trend for the Non-Hyperactives Averased over Direction, Repetition, and Subjects 35

6. Tests for Age Trend for the Hyperactives Averaged over Direction, Repetition, and Subjects 35 
1. Developmental curve for primary illusions

2. Projected comparison curves with peals illusion at four years for normals

3. Projected comparison curves with peak illusion at five years for normals 10

4. The Muller-Lyer aoparatus 19

5. Configurations of maximum spatial effect for the open and closed components of the Muller-Iyer 21

6. Percent illusion as a function of direction of adjustment by blocks of repetition

7. Percent illusion as a function of population by ase 
ABSTRACT

MULIER-LYER ILIUSION

IN HYPERACTIVE BOYS

by

Robert Roy Houghton

Naster of Arts in Psycholozy

June, 1976

Effects of exposure time, repetition, ase, and direction of adjustment on primary Muller-Lyer lilusion were studied in six, seven, elght, and nine year old hyperactive and non-hyperactive boys. Expectations from prior ilndings of continuous decrease in illusion within the age range examined were confirmed. Il zht and nine jear old non-hyperactives were each less susceptible to illusion than six year old non-hyperactives. A Innear trend of decreasing iliusion in non-hyperactives with age lent further support. Illusion and illusion differences were explained through Plaget's theory of perception. Increasing application of perceptual activity, an antasonistic factor to illusion, can explain gradual reduction of illusion with increasing ase. Differences in illusion with age in hyperactives 
resembled Plaset's developmental curve for primary illusion moved forward in years which supported the notion of a las rather than an aberrancy in normal perceptual development. Less illusion in six year old hyperactives than in six year old non-hyperactives supported Plazet's theoretical expectation of less illusion in normal populations younger than flve years. Fewer perceptual encounters, resulting in less structure to the figure and less distortion from field effects, and/or less adequate representational schemeg can explain reduced illusion in six year old hyperactives. Greater encounters and more adequate representational schemes can explain peak of lllusion by six year old nonhyperactives and seven year old hyperactives. By elght and nine years of age, differences in illusion were not apparent. Reduction of illusion with progressive repetition for adjustment outwards was not different for populations and/or ages examined. Direction of adjustment interacted with repetition to mask overall repetition effects. Failure to find a difference in effects of exposure time on 1Ilusion was interpreted to mean that hyperactives did not move through the Plagetian exploratory continuum at a different pace. The matching familiar figures test was included to add descriptive definition to the populations studied. Population and/or age differences were not found in latency to first response, or tendency to reflect. However, the more reflective the boys were as a group, the fewer the perceptual recognition errors. 
MULLER-LYER ILLUSION IN HYPERACTIVE BOYS

The major pursuit of plaget's work has been the nature and development of intelligence. His concern with oerception, a subordinate interest, has focused on two problems: the relation of perception to intelligence and the epistomologlcal status of perception as a form of knowing in and of itself. Experimentation with the classic opticoseometrical illusions has been the central testing sround for his theorizing about perception. optico-geometrical 1llusions for plaget (1969) are roughly classed in two categories basea on the relationship of perceptual deviation from veridicality and age. The effects of primary illusions diminish continuously to an average level with are and the effects of secondary illusions increase continuously to an average level with age.

For Piaget (see Flavel1, 1963, po. 226-236), primary illusions are the consequence of field effects which distort perceptual judgment. Fleld effects, also referred to as primary perception, include elementary error I and elementary error II. Perceptual "encounters" with a centered stimulus lead to overestimation relative to surroundins stimuli (elementary error I). Perceptual "couplins", or active coordination of encounters, leads to a more veridical comparison between stimuli through decentretion. "Active coordination" is meant to imply some direction by higher-order cognitive processes. Lack of 
sufficient coupling regults in elementary error II. The reduction of fleld effects with ase through active perceptual processes is the explanatory mechanism for the developmental decrease in primary lilusions. An ldealized curve of developmental trend is represented in Figure 1 . In contrast, secondary 1llusions increase with age and result from perceptual activity. Illusionary effects with current stimuli which demand active retention of earlier stimuli in memory because of a separation of presentation in space or time enhance with aze.

Perceptual coupling is one of a set of sensory-motor activities which are employed by the percelver in an active attempt to counteract the distortions of passive primary perception. Piaget speaks of kinds of perceptual activities such as spatial transports and temporal transpositions of elements and/or whole conflgurations to other elements and/or conflzurations. Repeatable sensory-motor activities produce schematizations which may be empirical, geometrical, deformins, or compensatory. Schematization allows anticipatory sets and retroactions, or the influence of memory. Perceptual exploration of an object is a continuum that begins with relatively passive perceptual encounters, which construct a figure from its component parts and induce distortins field effects, and continues With more active perceptual activities, which lead to relative objectivity. Perceptual couplings or stimulusstimulus comparisons, kinds of perceptual activities, are 


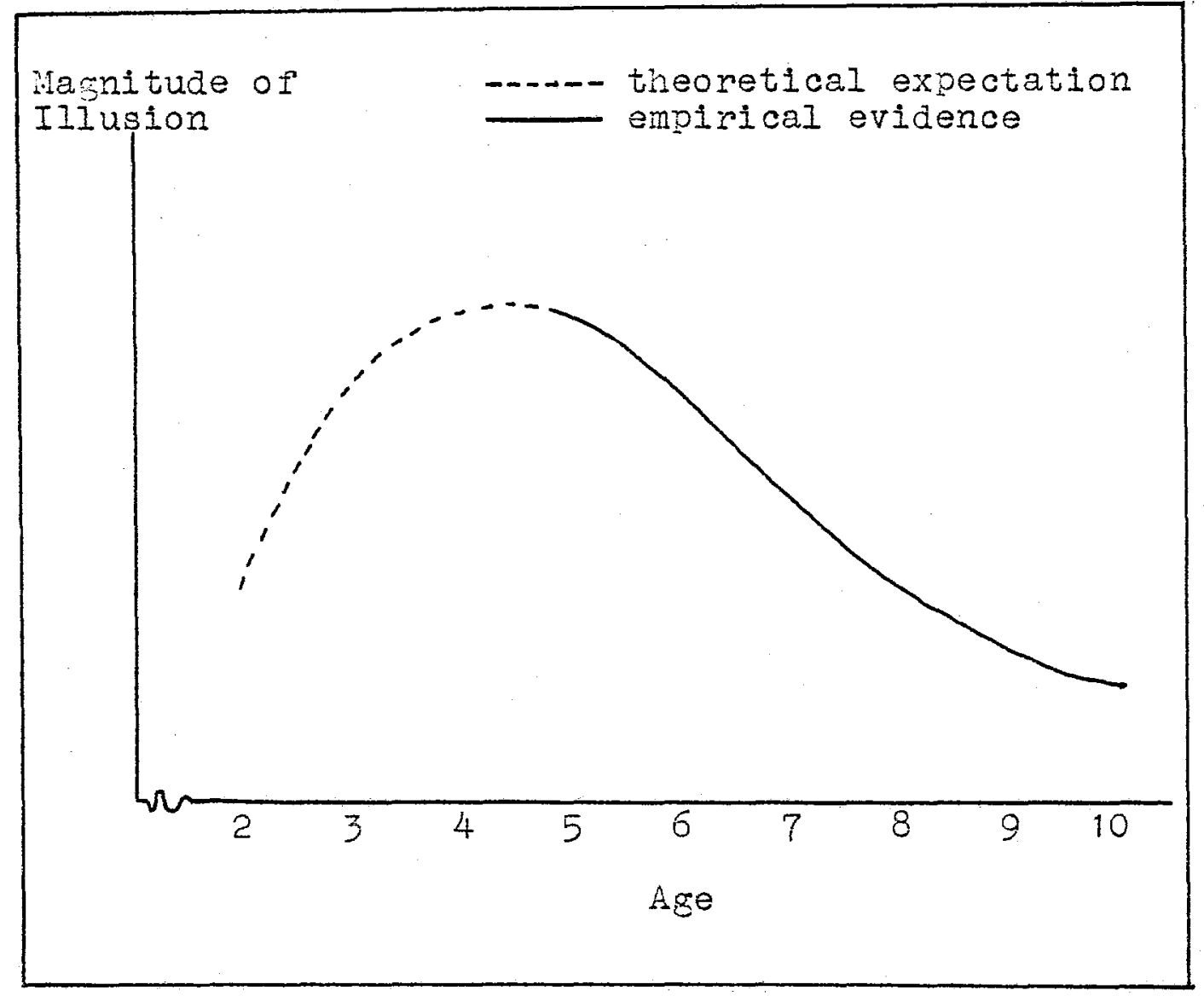

Figure 1. Developmental curve for primary illusions (Piaget, 1969, 2. 200). 
on the lower end of the exploratory continuum which melds into acts of intellisence proper. Structurally, primary perception is analogous to the thought of the early preoperational child and, at best, perceptual activity, which brings the semi-reversible compensations for primary field effects, is analogous to the thought of the late preoperational child.

Perceptual development, then, is characterized by an increasingly active role on the part of the perceiver. In contrast to cognitive development, perceptual development is restricted and does not breal down into a sequence of definite, qualitatively different stages. For Piaget, both operational intelligence, with 1 ts concomltant mental representations, and perception srow out of sensory-motor intelligence. While perception is somewhat of a separate epistomological subsystem, it is a dependent subsystem of evolving sensory-motor intelligence. Plaget (cited in Flavell, 1963, p. 232) states, "We w1ll call perception the most direct or immediate possible knowledge of a present object in the sensorial field (without affirming, however, that there exists a knowledge which is completely direct or immediate)".

Study of the optico-geometrical illusions by Piaget has employed the genetic method. The genetic approach as defined by Plaget (1969) is meant to imply not only the simple comparison of developmental trends, but the study of the effects of learning, exposure time, and spatial 
variables. In the case of primary tllusions, some developing antasonistic factor must account for the decrease in illusion with age. In addition, the genetic method includes repetition in a settine which excludes external reinforcement to compare the effects of learning with those of development. For Plaget, learning in this setting involves a process of equilibration or spontaneous compensations in the sense that any changes in fllusion with repetition are not externally reinforced. Because perceptual activity, the antagonistic factor proposed by Piaget, takes time, the effects of exposure duration are relevant. Manipulation of spatial variables adds further breadth to the method. The present study was patterned after Noelting's application of the zenet1c method to the MullerLyer flgure cited by Piaget (1969) as representative of this approach.

\section{Hyperactivity}

The foregoing theoretical discussion invites the question of possible population differences which might influence the effects of age, learning, and exposure time. The genetic method was applied in this study to six, seven, eisht, and nine year old hyperactive and non-hyperactive boys. Hyperactive behavior has been varlously defined as either bordering on the abnormal or just excessive in character. An example of the former definition appears in a statement by Millichap (1975): 
Hyperactive behavior, or hyperinesis, is an unusual degree of motor restlessness that is purposeless and not directed toward a speciflc, meaningful goal. This random, excessive activity interrupts the child's attention and concentration and disrupts his ability to perform structured tasks. The failure to sustain attention on purposeful tasks and goals is the behavioral manifestation that differentiates the hyperactive child from the norm.

An example of the latter definition by Werry is discussed by Ross (1976):

The most appealing hypothesis is one advanced by Werry (Werry et al., 1972). According to this, activity level is seen as a normal dimension of behavior alons which all children are distributed, and those at the hish end of the continum encounter difficulty because of the social environment. The repeated criticism and negative evaluation encountered by such chilaren might lead some of them to develop academic difficulties.

The genetic method is highly appropriate for delineation of developmental trends in the perceptual growth of hyperactive children. Is hyperactivity related to an aberrant perceptual development or a lag in nomal development? Is hyperactivity related to an aberrant perceptual 
exploration of a structured task or a perceptual exploration that can be described as dilatory? The hypothesis proposed in this study is that normal perceptual development proceeds at a slower pace for hyperactive than for non-hyperactive children and, given the level of perceptual development, movement through the nomal exploratory continuum proceeds at a slower pace for hyperactive than for non-hyperactive children.

Aze

Consistent findings, along with Noelting's data reported by Piaget (1969), of a developmental decrease in 11lusion in the age range from five to ten years (Pollack, 1963, 1964; Wohlwill, 1960) provide evidence for classifying the Muller-Lyer as a primary rather than a secondary 1lIusion. While not supported empiricaliy, Piaget (1969, pp. 200-201) predicts weaker illusion for children younger than four or five years of age because of the difficulty In structuring the parts of the flgure "on the basis of their fundamental constituent relations". The dimensional inequalities would be less pronounced at an age when apprehension of Euclidean figures was less immediate. This reasoning implies the curvilinear trend shown in Fisure 1 if the developmental trend were extended below five years. The implications in terms of perceptual exploration for children younger than five years are two-fold. Not only are perceptual encounters insufficient to structure the Iigure and insufficient to produce maximum field effects, 
but assimilation of the figure is problematical because representational schemes for Euclidean ifigures are rudimentary.

Noelting found peal illusion for the Muller-Lyer at five years, the younzest age studied, followed by a continuous decrease of 1liusion with age until nine years, the oldest age studied. Peal illusion implies sufficient perceptual encounters to structure the fizure, sufilcient perceptual encounters to produce maximuin field effects, and representational schemes that allow assimilation of the flgure. Decrease of illusion after the peak implies the increaging application of perceptual activity to reduce field effects. It is postulated here that normal perceptual development proceeds at a slower pace for hyperactive children. The possibilities of a two year developmental lag in normal perceptual growth are represented in Figures 2 and 3 .

At this point it is apparent that the zenetic method gains richness when paired with the hypothetical constructs of Piaget's perceptual theory. The developmental trend reflects the developmental acquisition of Piaget's perceptual mechanisms. The similar deviation from veridicality by four year olds and seven year olas is explained through different sets of perceptual mechanisms acquired by the perceiver. The peak deviation from veridicality by five year olds substantiates a further srowth in the perceptual mechanisms of four year olds, but the appearance of an 


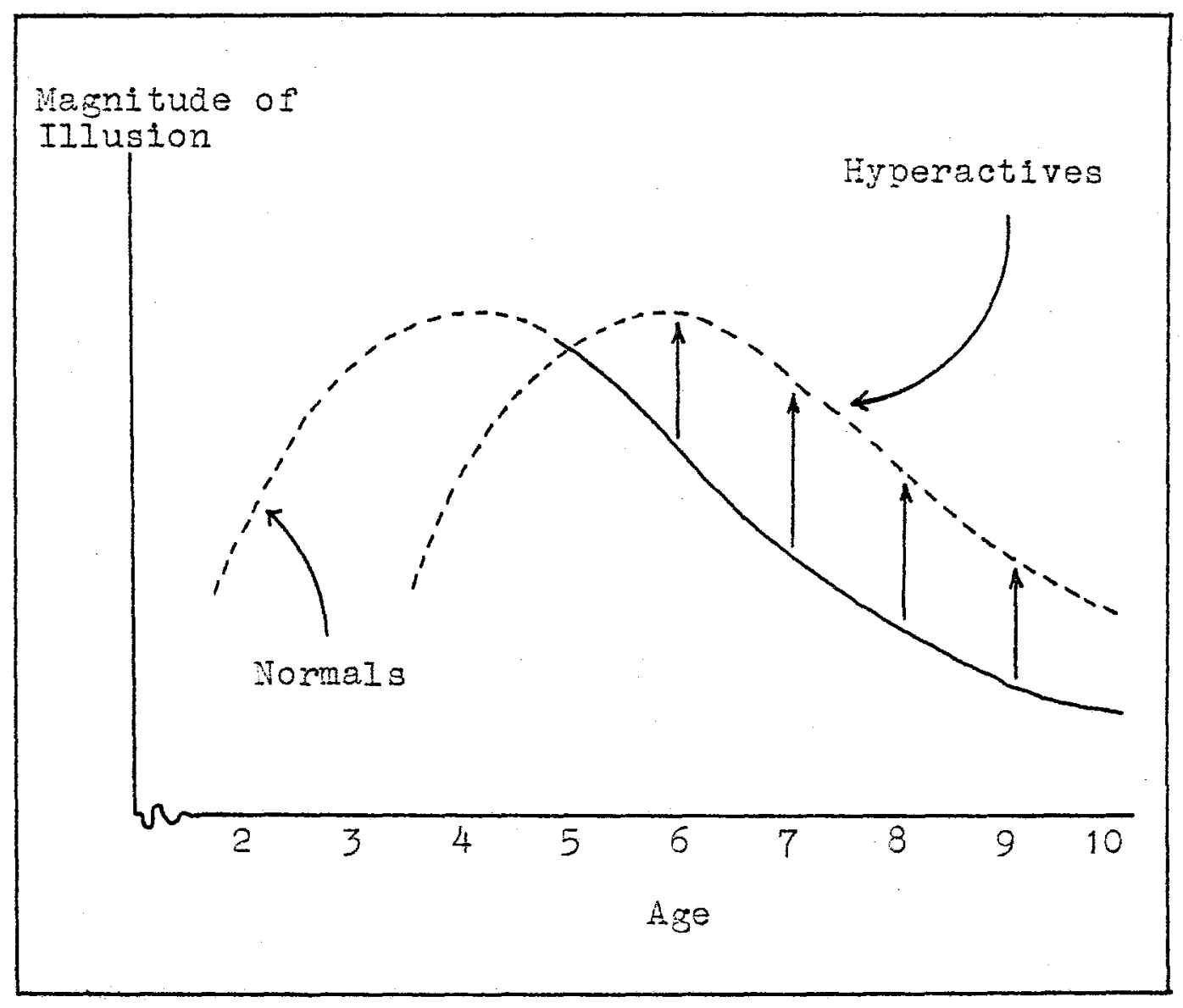

Figure 2. Projected comparison curves with peak illusion at four years for normals. 
Masnitude or

IIIusion

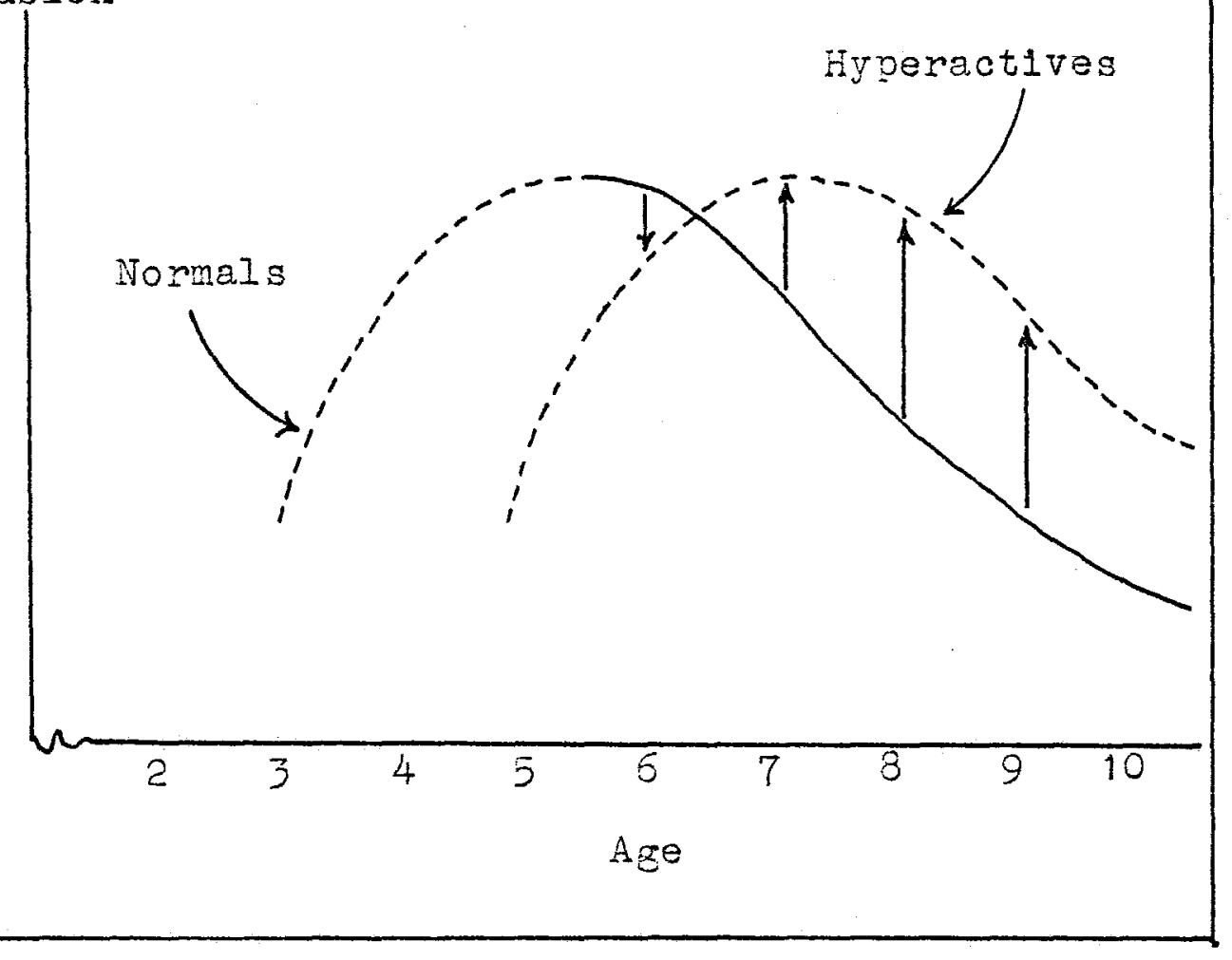

Figure 3. Projected comparison curves with peak illusion at ilve years for nomals. 
antagonistic factor is necessary to explain the reduced deviation from veridicality by seven year olds. By examination of the qualitative and quantitative differences between the developmental trends for the hyperactives and non-hyperactives, the genetic method becomes sensitive to questions of an aberrant perceptual development in contrast to a las in normal perceptual development for the hyperactives. Because the research findings in the literature pertaining to hyperactive children did not employ the genetic method, they are reported here as indications of aberrancy or las in acquisition of particular perceptual mechanisms with some reservation.

Indications that hyperactives would experience difficulty in structuring a figure can be found in a study by Campbe11, Douglas, and ilorgenstern (1971) on cosnitive styles in hyperactive chlldren. The hyperactives isolated significantly fewer figures on the Children's Imbedded Figures Test (CEFT) when compared with normals. More studies are available which show deficiencies on tests of embeddedness for children with learnins disabilities many of whom exhibit hyperactive behavior (cited in Tarver \& Hallahan, 1974). Difficulty in perceiving component parts in tests of embeddedness implies difficulty in constructing the Muller-Lyer figure from its component parts.

Findings that hyperactives are deficient in the active application of perceptual mechanisms are also indicated by Tarver and Hallahan (1974). They adopted a 
post-hoc hypothesis of hypo-responsiveness from Browning (1967) to lint many of the findings they reviewed and are mentioned here on hyperactive and learnins disabled children. Hypo-responsiveness, orlginally postulated by Brownins as a behavioral correlate of brain damage in children, is defined in gimplest terms as emitting "iewer and less varied responses per time interval per stimulus situation" (Browning, 1976, p. 251). Specific hypotheses of developmental las generated from survey of Fisures 2 and 3 were (a) a difference in magnitude of lllusion between the six year old hyperactives and the six year old nonhyperactives and (b) greater magnitude of illusion for the seven, eight, and nine year old hyperactives than for their non-hyperactive counterparts in age. Are the effects of age, within the are range examined, different for the hyperactives and non-hyperactives?

Repetition

Noeltins found that children showed no benefit with as many as 20 repetitions in a settins that excluded external reinforcement until at least six years of age. However, Indications of spontaneous reduction of illusion with progressive repetition were not statistically sienificant until seven years of age. That progressive repetition did not result in sponteneous reduction of the illusion with children younger than seven years of age was interpreted as a lack of active perceptual activity in their behavioral repetoire. After seven Jears of aze, practice effects 
Increased as a function of age. The older the child, the more suppression of the illusion with repetition and, presumably, the better application of perceptual activity. However, hyperactives found a conceptual learning task difilcult in a condition without continuous feedback (Freiberss a Louglas, 1969). Douglas (1972) found that hyperactive children deteriorated more seriously across time in a visual and alidtory continuous performance task than normal controls. If the effects of repetition depend upon age, are the effects aifferent for the hyperactives and non-by peractives of the same age? It 13 postulated here that normal perceptual development proceeds at a slower pace for hyperactive children and, given the level of perceptual develooment, movement through the normal exploratory continuum proceeds at a slower pace for hyperactive chilaren.

Exposure Time

Exposure time was indirectly assassed in Noelting's setting of unconstrained vision. A temporal maximum with tachistoscopic presentation of the Wuller-Iyer with children has been set between 0.04 sec and 0.1 sec by Muller (clted in Piaget, 1969, pp. 123-125) which fits a Form I distribution for temporal maxima in Piaget's formulation. The temporal maximum, the amount of exposure time necessary for maxtmum illusion, is the largest difference between a curve representing the growth of "encounters" and a curve representing the growth of "couplings" across time. 
Noelting's finding that the illusion inoreased in the first four or five repetitions in a setting of unconstrained vision was interpreted as a form of the temporal maximum In those children who failed to structure the detail of the fizure on the inftial repetitions. This interpretation demands that number of repetitions be accepted as somewhat equivalent to a direct measure of exposure time. Tachistoscopic presentation is obviously more exact.

Cohen (cited in Douslas, 1972) found hyperactive children less responsive (physiological measures) to a signal in a delayed reaction time task than normal controls. Because irrelevant as well as relevant cues tend to be processed when arousal level is low (Easterbrools, 1959) and because hypo-responsiveness aptly describes a number of research findings pertinent to the hyperactive population, a prolonged temporal maximum (temporal delay), inferred from number of repetitions, was expected of the hyperactives in this study. Repetitions here were blocked into sets of six repetitions each. Hypotheses based on temporal delay were (a) sreater magnitude of illusion in the second block of repetitions than in the first block of repetitions for the hyperactives and (b) lesser magnitude of illusion in the second block of repetitions than in the finst block of repetitions for the non-hyperactives. It is postulated here that, given the level of perceptual development, movement through the normal exploratory continuum proceeds at a slower pace for hyoeractive children. 
Spatial Variables

The orimary illusions have forms of developmental trend which do not change qualitatively with manipulation of the spatial components of the figure (Piazet, 1969). Illusion changes quantitatively with different configurations, but a configuration which produces maximum illusion at one age produces maximum illusion at other ages. While manipulation of spatial variables was not an independent variable in this study, mention was made here of the constant effects of spatial variables because qualitative comparisons were made between the developmental trends of this and other gtudies. Direction of Adjustment

The effects of direction of adjustment have been shown to differentiate organic mental defectives from normal controls in a study by Jeniin and West (1969). While adjustment outwards did not produce differential illusion, adjustment inwards produced much weaker illusion in the organic mental defectives. Because of the commonly made comparisons between the behavioral correlates of known brain-damaged children and of hyperactive children, direction of adjustment, outwards and inwards, was included as an independent variable in the design of this study. Are the effects of direction of adjustment different for the hyperactives and the non-hyperactives? If the effects are different, does the difference depend upon repetition?

The population of hyperactives available to the 
experimenter was primarily receiving drus theraoy. A measure of reflection-impulsivity, or latency to ilist response on the matching ramiliar figures test, was included to add descriptive definition to the hyperactive population studied. Hyperactives receiving methyl phenidate (Ritalin) treatment and normal controls were each more reflective (sreater latency to flrst response on the matching familian ilgures test) than unmedicated hyperactives in a study by campbell et al. (1971). Intelifience, Within the normal range, is not a significant correlate with magnitude $O \vec{I}$ illusion for the primary lllusions and specifically for the Nuller-Lyer (Pollack, 1963, 1964). 


\section{METHOD}

\section{Subjects}

Ninety-six boys were drawn from the pediatrlc practices of Frank Dudenhoeffer, MD, and R. Wendell Coffelt, MD, located in La Canada and Burbank, California, respectively. The experimental group consisted of 48 boys, diaznosed "hyperkinetic", divided into four aze groups ( $3 \pm x$, seven, eight, and nine year olds) of 12 subjects each. Determination of the "hyperkinetic syndrome" Involved weighted assessment of behavior rating scales from parents and teachers, case histories, and examinations for "soft" neurological signs. Both physicians had considerable experience in the dianosis and ireatment of hyperactive children. Subjects were not accepted if their medical charts indicated gross sizns of brain damage, visual problems, possible mental retardation, or if their hyperactivity was secondary to suspected psychiatric or psycholosical disorders. All except six of the hyperactive boys were receiving drug therapy at the time of the study (see Appendix A for physician and medication information).

The comparison group consisted of 48 normal boys, free from complaints of hyperactivity, visual problems, of signs of mental retardation, divided into four age groups (six, seven, eight, and nine year olds) of 12 subjects each. Parents were approached during regular office visits or through telephone contact by the physicians or staff 
nurses. The study was explained as perceptual in nature and parents were assured that the results would be anonymous. About ten parents refused permission for reasons of time or transportation and another five parents refused because they preferred to not have their children take part. If permisgion was granted, individual appointment schedules were set up at 20 minute intervals and all children were seen in the physician's office.

One six year old hyperkinetic boy was unable to understand the instructions with the vuller-Lyer figure. The data from that session were discarded. Of the 100 boys' parents who volunteered, eisht did not keep their appointments. Four of these zept a second appointment after re-contact, and four were substituted by new volunteers. Apparatus

Magnitude of illusion was measured with a Muller-Iyer 1llusion (Model \#14010) obtained from Lafayette Instrument Company (Lafayette, Indiana). The white lines of the illusion were painted on a black background 13 inches high and 24 inches lone. The 1llusion was presented horizontally With the movable open component (forked ends) on the right (see Figure 4). The stationary closed component (arrowed ends) on the left consisted of a white line $230 \mathrm{~mm}$ long between arrows. Forks and arrows were set at angles of 90 desrees with angle line lengths of $30 \mathrm{~mm}$. A centimeter rule was placed on the back of the adjustable arm to quantify the magnitude of illusion. Black construction paper 


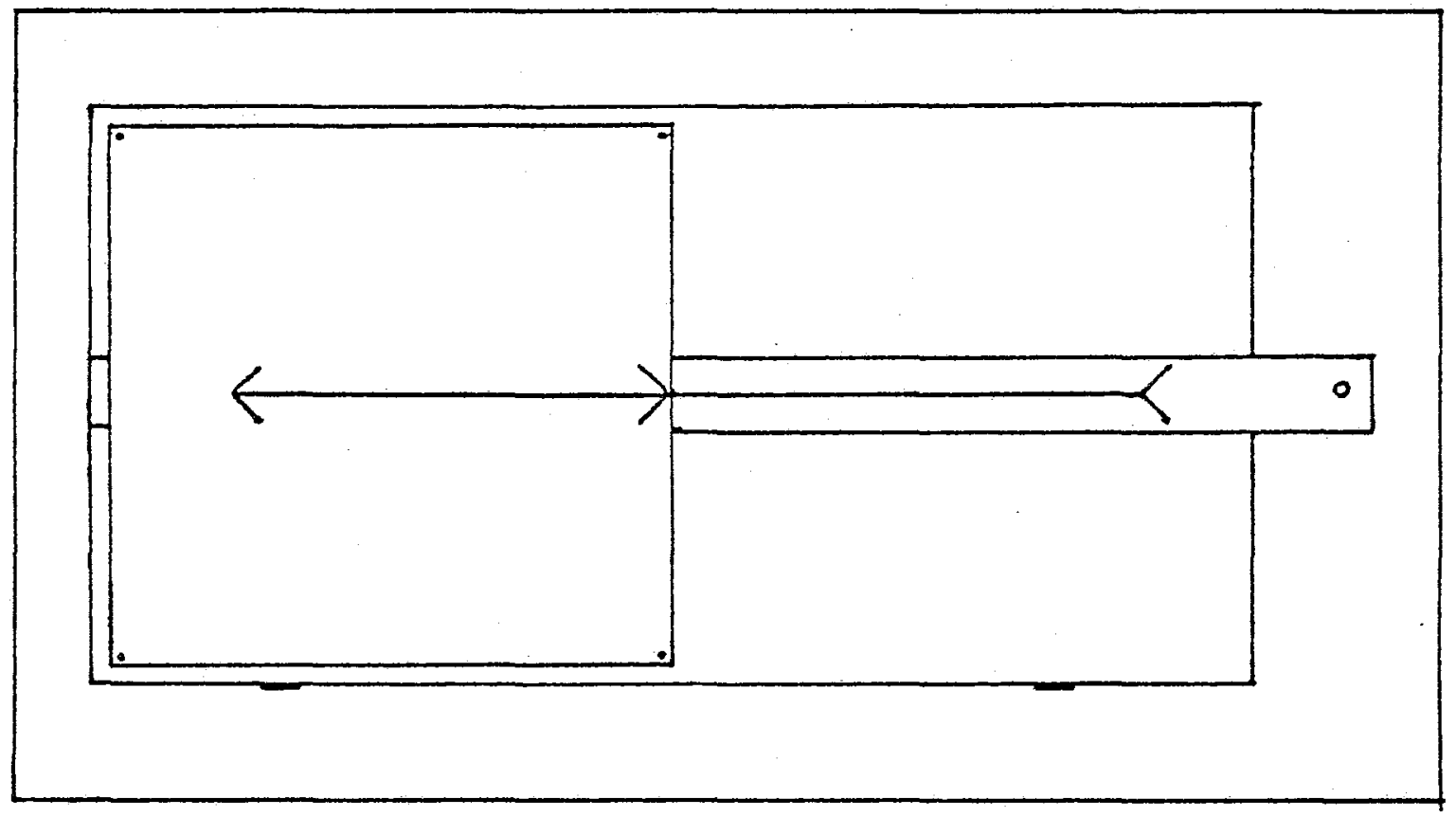

Fisure 4. The Muller-Lyer apparatus obtained from the Lafayette Instrument Company in Lafayette, Indiana (Model \#14010). 
masked the less and top of the illusion apparatus to reduce backsround cues.

Vianlpulation of the spatial varlables of the figure produces a configuration of maximum effect when $B=2 \mathrm{~A}$ for the open component and when $B=.5 \mathrm{~A}$ for the closed component as represented in Figure 5 (Piaget, 1969, pp. 44-49). The coefficients for the configuration in this study were $B=1.18 \mathrm{~A}$ and $\mathrm{B}=.32 \mathrm{~A}$, respectivel $\mathrm{y}$. The interpretation of the Muller-Lyer illusion by Piaget is based on the Introduction of vintual line, $B$, as a factor on an equal footing with the real lines. Field effects engender overestimation of $A$ and underestimation of $B$ in the open component, and the reverse in the closed component, because of a perceptual devaluation of the length difference between $A$ and $B$. Iine $A$ of the open component appears longer than an objectively equal comparison line and line $A$ of the closed component appears shorter than an objectively equal comparison line. The components in this study were compared to each other rather than having each component compared to a single line vithout arrows on forts which is the usual experimental practice. Because line $A$ of the open component was adjusted to line $A$ of the closed component, negative illusion was expected. In other words, the expectation was that line $A$ of the open component would be adjusted to a length shorter than a length of objective equality to line A of the closed component. The unpublished matching familiar figures test (Kagan, 


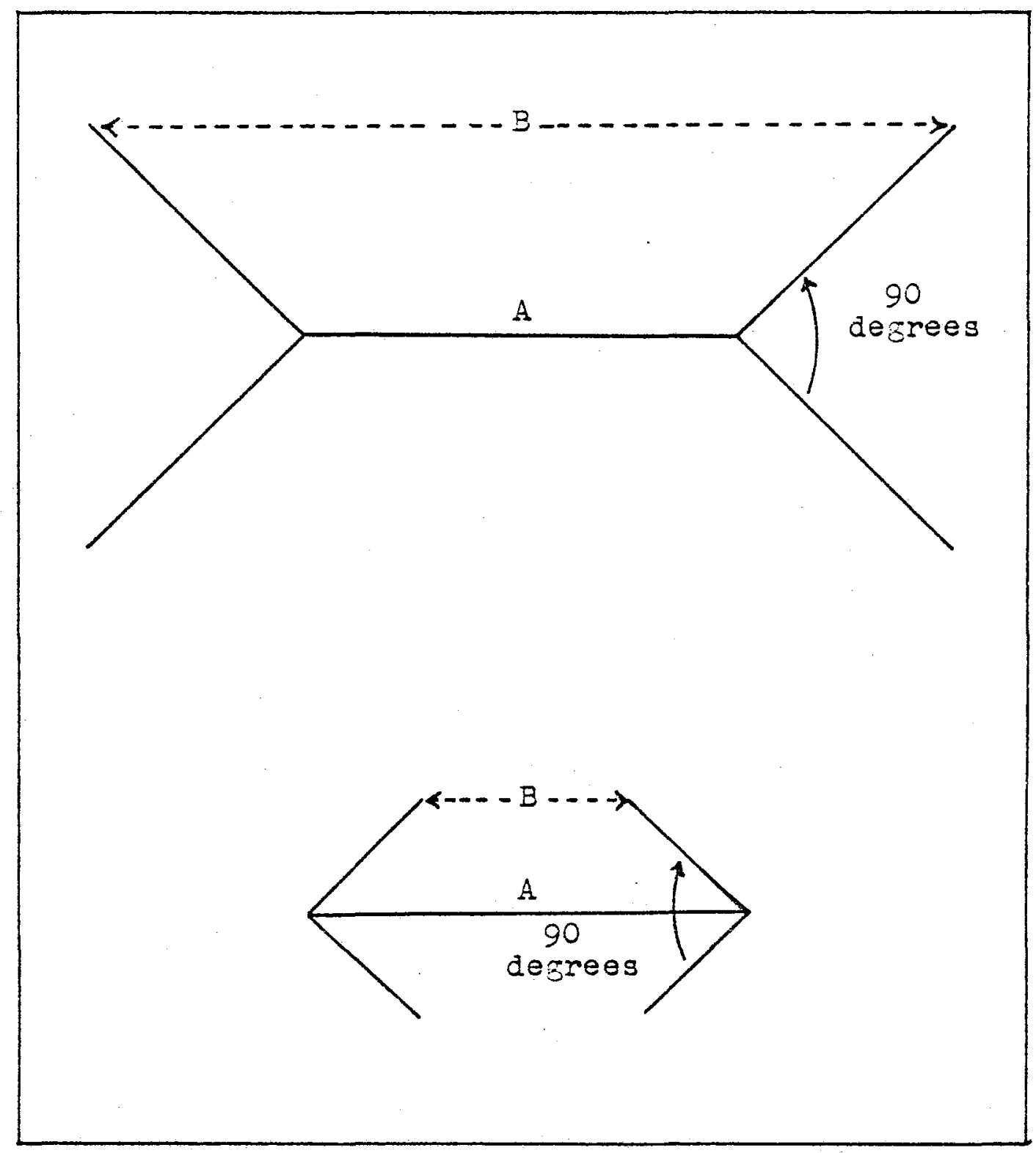

Fizure 5. Configurations of maximum spatial effect for the open and closed components of the Muller-Lyer (P1aget, 1969, p. 44-49). 
Rosman, Day, Albert, 2 Phillips, 1964) was obtained from the author throush personal correspondence to measure reflection-impulsivity. The test consisted of 14 sets of plctures of iamiliar objects and aninals, two practlce and 12 test sets (see Appendix B).

\section{Procedure}

Each experimental session began with the two practice items, followed by the 12 test 1tems, of the matching familian figures test in accordance with the instructions outIned in the tegt booklet (see Appendix C). A stopwatch Was used to measure latency to first response to the nearest half-second. Total number of errors and order of errors were recorded. Each item consisted of a standard stimulus presented simultaneously at pight angles to six alternative stimull. The subject was to select his "match" amongst the alternative stimuli by pointing. If the subject made an incorrect choice, he was encouraged to look again. Up to six errors were allowed per item. Raw data consisted of the total latency to first response (reflection-impulsivity) and the total number of perceptual recognition errors for the 12 test Items for each subject.

The Muller-ijer apparatus was then presented in a settins of unconstrained vision and the seometrical flgure was described (see Appendix $D$ for instructions). Each subject was instructed to adjust the movable arm on the right to the position where the lines were of equal length. Handedness was determined by observation in the matching familiar 
figures test and of those four subjects who used their left hand for pointing, all used their right hand to adjust the movable arm. The direction of the first adjustment, outwards (A) or inwards (B), was counterbalanced by alternatins direction of adjustment between subjects within each population-age zroup. Half the subjects began with direction outwards and half with direction inwards. The direction of subsequent adjustments was balanced by alternating direction of adjustment within subjects within each population-age group. An A $B$ order was used.

The centimeter rule regigtered zero at the point of objective equality ( $P O E$ ) between the figure components. Starting position was $-230 \mathrm{~mm}$ from the POE for direction outwards and $+230 \mathrm{~mm}$ from the POE for direction inwards. Return to starting position for successive adjustments was the experimenter's responsibility. After each adjustment to the point of subjective equality (PSE) between the figure components, the centimeter rule reglstered positive and negative deviations from the POI. A positive deviation meant the PSE was greater than the POE and a negative deviation meant the PSE was less than the POI. Magnitude of illusion was the registered deviation from the POE, that is, the positive or negative difference between the PSE and the POE. Magnitude or Illusion was recorded to the nearest millineter for 30 adjustiment repetitions divided into five blocks of six repetitions each. So for subjects within a population-age sroup, direction of adjustment within the 
first block of repetitions was $A, B, A, B, A, B$ for half the subjects and $B, A, B, A, B, A$ for the other half. Raw data for statistical analyses consisted of the algebraic sum $O \hat{I}$ the three outward adjustments within a block of repetitions and the algebralc sum of the three inward adjustments within a block of repetitions. Two pieces of data for each blocis of repetitions for each subject totaled to ten pieces of data for the five blocks of repetitions for each subject. Percent illusion was calculated for graphic representation of the data in this study by dividing the magnitude of lllusion (algebralc sum deviation for three adjustments recorded in millimeters) by $690 \mathrm{~mm}$ or three times the line length of the stationary closed component $(230 \mathrm{~mm})$. Age and experimental population information were known by the experimenter at the time of the data collection. Design

A four-way analysis of variance (mixed design with two between and two within subject variables) was carried out to determine the effects of population, age, repetition, and direction of adjustment on the magnitude of illusion with the Muller-Lyer fizure. Dunnet's tests for comparisons of means involving a control mean were planned to test the hypotheses of developmental $1 \mathrm{Ig}$ and temporal delay (Kirk, $1968,0.94)$. A two-way analysis of variance (independent groups design) was carried out to determine the effects of population and ase on reflection-impulsivity (latency to 
first response) on the matchins familiar figures test. Pearson product-moment correlations based upon the 96 subjects were computed between latency to first response and number of errors on the matching familiar flgures test, between latency to first response on the matching familiar fizures test and magnitude of lllusion with the Muller-Lyer averaged over blocks of repetition and direction of adjustment, and between number of errors on the matching ramiliar figures test and magnitude of illusion with the Mulier-Lyer averaged over blockg of repetition and direction of adjustment. The .05 alpha level of sienificance was set for rejection of the null hypothesis in all cases. 


\section{RESULTS}

Peflection-Inoulsivity

on the matchinf familiar figures test, the more reflective (seater latency to first response) a subject, the less perceptual recosnition errors were made in

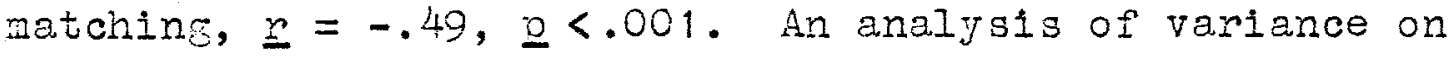
the reflection-impulsivity measure, summarized in Table 1 , indicated no statistically sienificant overall age or population efiects and no statistically significant age $x$ pooulation interaction.

For the 96 subjects, neither number of errors nor tendency to reflect on the matching familiar figures tegt was sigificantly correlated with magnitude of illusion on the Muller-Lyer figure. The non-significant product-moment correlations were $\underline{\underline{\varepsilon}}=+.12, \underline{\mathrm{g}}>.05$ and $\underline{\underline{r}}=+.04, \underline{\mathrm{q}}>.05$, respectively.

Macnitude of IIIusion

An analysis of variance on maenitude of illusion, summarized in Table 2, indicated a highly significant overall direction of adjustment effect, $\underline{E}(1,88)=75.81$, $\mathrm{Q}<.001$. However, effect of direction of adjustment interacted with blocks of repetition as shown in Figure 6 . Pairs of means for this repetition $x$ direction of adjustment interaction, $E(4,352)=20.12, \underline{2}<.001$, were compared usins a post-hoc Newman-KeuIs nultiple comparisons test (Kirk, 1968, p. 91) summarized in Table 3. Magnitude of illusion 


\section{Table 1}

Analysis of Varlance for Effects of Population and Age on Response TIme to the Watching Familiar Figures Test

\begin{tabular}{lcccc}
\hline Source & SS & df & MS & E \\
\hline Population (P) & 23484.40 & 1 & 23484.40 & 1.41 \\
Ase (A) & 11503.26 & 3 & 3834.42 & 0.23 \\
PXA & 14820.09 & 3 & 4940.03 & 0.30 \\
Subjects (PA) & 1461935. & 88 & 16612.90 & \\
\hline
\end{tabular}


Table 2

Analysis of Vanlance for Iffects of Population, $A \cong e$, Repetition, and Direction on Magnitude of Illusion

\begin{tabular}{|c|c|c|c|c|}
\hline Source & Error Term & $d f$ & MS & $\underline{E}$ \\
\hline $\mathrm{P}$ & $S(P A)$ & 1 & 611.20 & 0.05 \\
\hline$A$ & $S(P A)$ & 3 & 35733.71 & $2.72^{*}$ \\
\hline $\mathrm{R}$ & $R S(P A)$ & 4 & 2045.11 & 1.44 \\
\hline $\mathrm{D}$ & $D S(P A)$ & 1 & 153520.40 & $75.81^{* * * * x}$ \\
\hline PXA & $S(P A)$ & 3 & $54777 \cdot 94$ & $4.18^{* * *}$ \\
\hline$P X R$ & $R S(P A)$ & 4 & 2193.23 & 1.54 \\
\hline$A x R$ & $R S(P A)$ & 12 & 1218.71 & 0.85 \\
\hline $2 \times D$ & $D S(P A)$ & 1 & 7672.70 & 3.79 \\
\hline$A \times D$ & $D S(P A)$ & 3 & 2137.43 & 1.06 \\
\hline$R \times D$ & $\operatorname{RDS}(P A)$ & 4 & 13016.85 & $20.12^{* * *}$ \\
\hline$S(P A)$ & & 88 & 13116.52 & \\
\hline PXAxR & $\operatorname{RS}(3 A)$ & 12 & 770.55 & 0.54 \\
\hline $\operatorname{PxAxD}$ & $D S(P A)$ & 3 & 686.00 & 0.34 \\
\hline PxRXD & $\operatorname{RDS}(P A)$ & 4 & 154.24 & 0.24 \\
\hline$A x R \times D$ & $\operatorname{RDS}(P A)$ & 12 & 534.62 & 0.83 \\
\hline$P S(P A)$ & & 352 & 1420.11 & \\
\hline$D S(P A)$ & & 88 & 2024.98 & \\
\hline PxAxRxD & $\operatorname{RDS}(P A)$ & 12 & 692.48 & 1.07 \\
\hline $\operatorname{RDS}(P A)$ & & 352 & 646.91 & \\
\hline \multicolumn{5}{|l|}{$*_{p}<.05$} \\
\hline 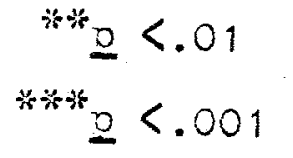 & & & & \\
\hline
\end{tabular}




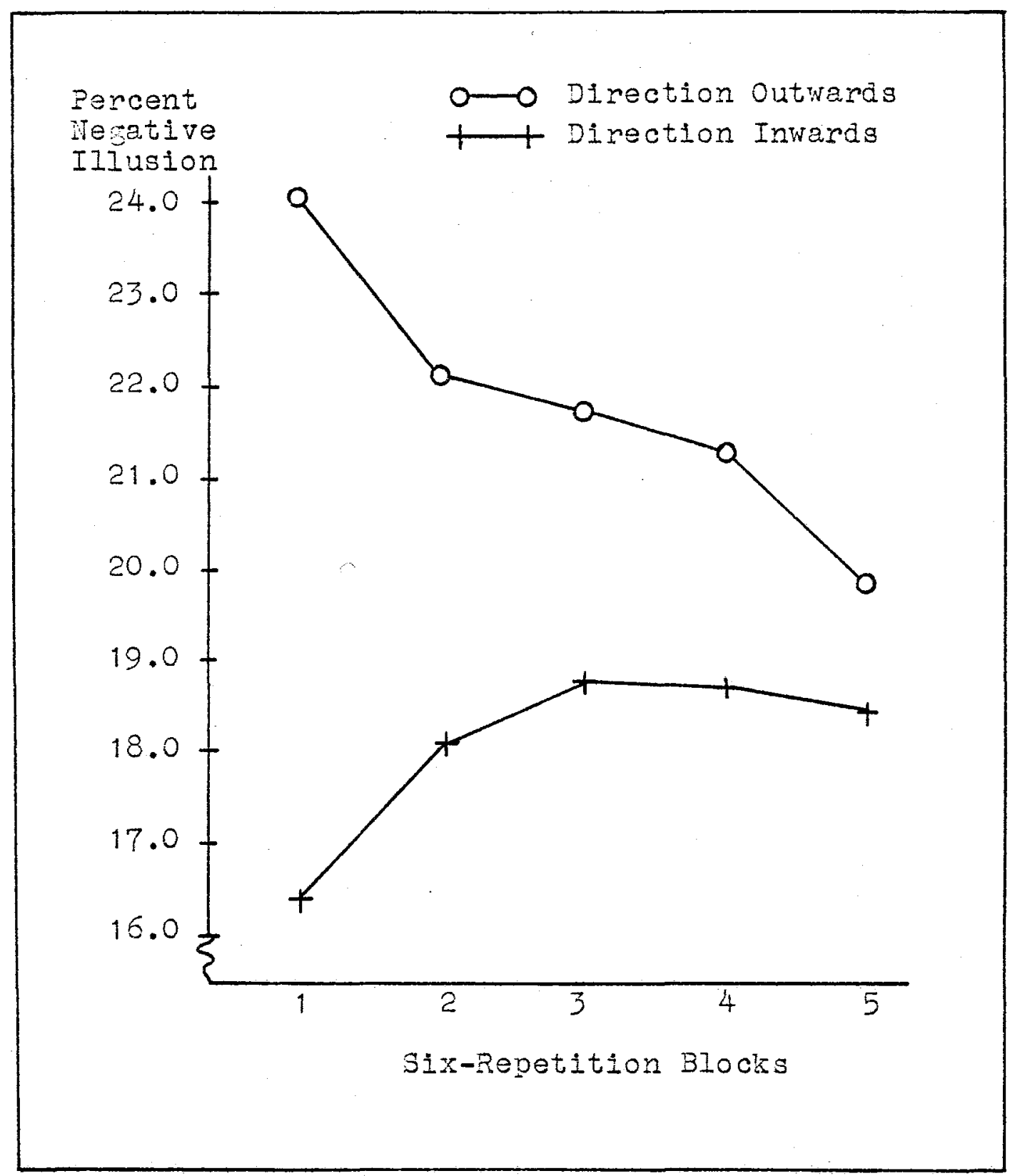

Fisure 6. Percent illusion as a function of direction of adjustment by blocks of repetition. 
Table 3

Newman-Keuls Comparisons between Illusion for Direction by Blocks of Repet1tion

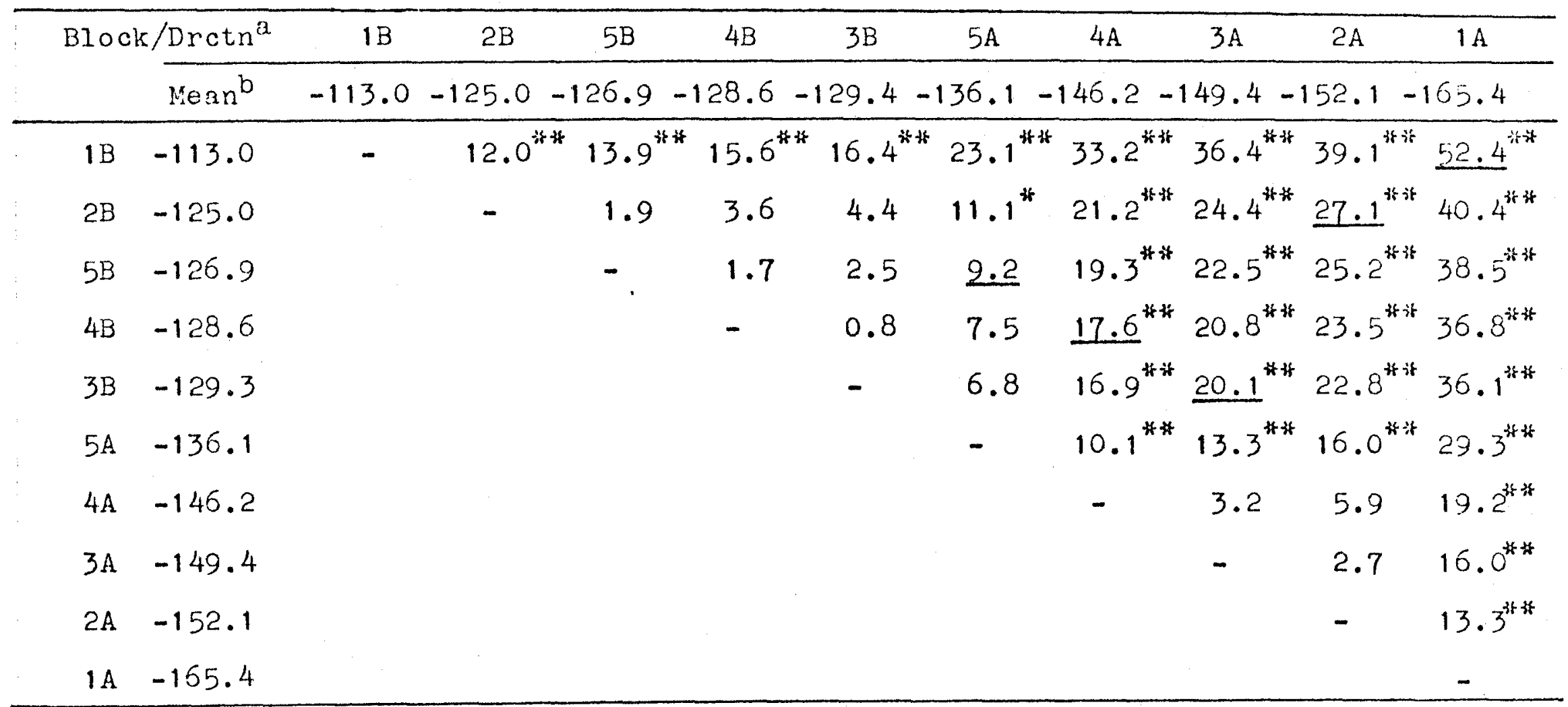

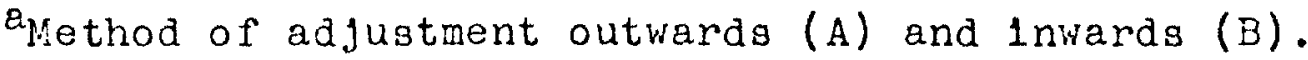

$\mathrm{b}_{\mathrm{Al}}$ gebralc sum 11 lusion averaged over population, age, and subjects.

${ }^{*} \mathrm{p}<.05$

*H $\underline{p}<.01$ 
for direction outwards significantly decreased from the finst block to the second, third, and fourti blocks and then significantly decreased again in the fifth block of repetitions. Magnitude of illusion for direction invards sisnificantly increased from the first block to the second, third, fourth, and fifth blocks of repetitions. While illusion for direction outwards was significantly greater than illusion for direction inwards in the first, second, third, and fourth blocks, this difference was not statistically significant by the fiftin block of repetitions.

The decrease of illusion with repetition for adjustment outwards and the initial increase of lllusion with repetition for adjustment inwards were not differentially affected by population and/or age difierences. Indeed, a statistically significant difference in magnitude of illusion with repetition did not occur unless the effect of direction of adjustment was taken into account because of the mutually opposins effects of the directional variable seen in the repetition $x$ direction interaction shown in Figure 6. Thus, the interactions hypothesized, that is the population $\mathrm{x}$ direction, the population $\mathrm{x}$ repetition $\mathrm{x}$ direction, the age $\mathrm{x}$ repetition, and the population $\mathrm{x}$ age $\mathrm{x}$ repetition interactions, were not statistically significant. Because the population $x$ repetition interaction was not statistically significant, the planned Dunnet's comparisons to test the temporal delay hypotheseg were not run. The hypothesized population $x$ age interaction was 
statisticelly significant, $\underline{\Xi}(3,88)=4.18,2<.01$, and is shown in Figure 7. A two-tailed Dunnet's test for comparisons confirmed the hypothesized difference in magnitude of IIIusion between the six year old hyperactives and the six year old non-hyperactives (mean difference $=42.23 \mathrm{~mm}$, g (.01). One-tailed Dunnet's comparisons indicated a statistically greater magnitude of illusion for seven year old hyperactives than for seven year old non-hyperactives (mean difference $=27.09 \mathrm{~mm}, \underline{p}<.05)$, but no statistically significant increase for the elfht or nine year old hyperactives as had been hypothesized. Mean differences for the latter age groups were $10.57 \mathrm{~mm}$ and $10.97 \mathrm{~mm}$, respectively. Further examination of the population $\mathrm{x}$ age interaction using a post-hoc Newman-Keuls test of the means for the non-hyperactive age groups only indicated significantly less magnitude of 1llusion for the eight year olds than for the six year olds and significantly less lllusion for the nine year olds than for the six year olds. Other comparisons, summarized in Table 4, were not statistically significant. Post-hoc trend tests, summarized in Tables 5 and 6 , Indicated a statistically signiflcant linear age trend for the non-hyperactives and statistically significant quadratio and cubic age trends for the hyperactives. 


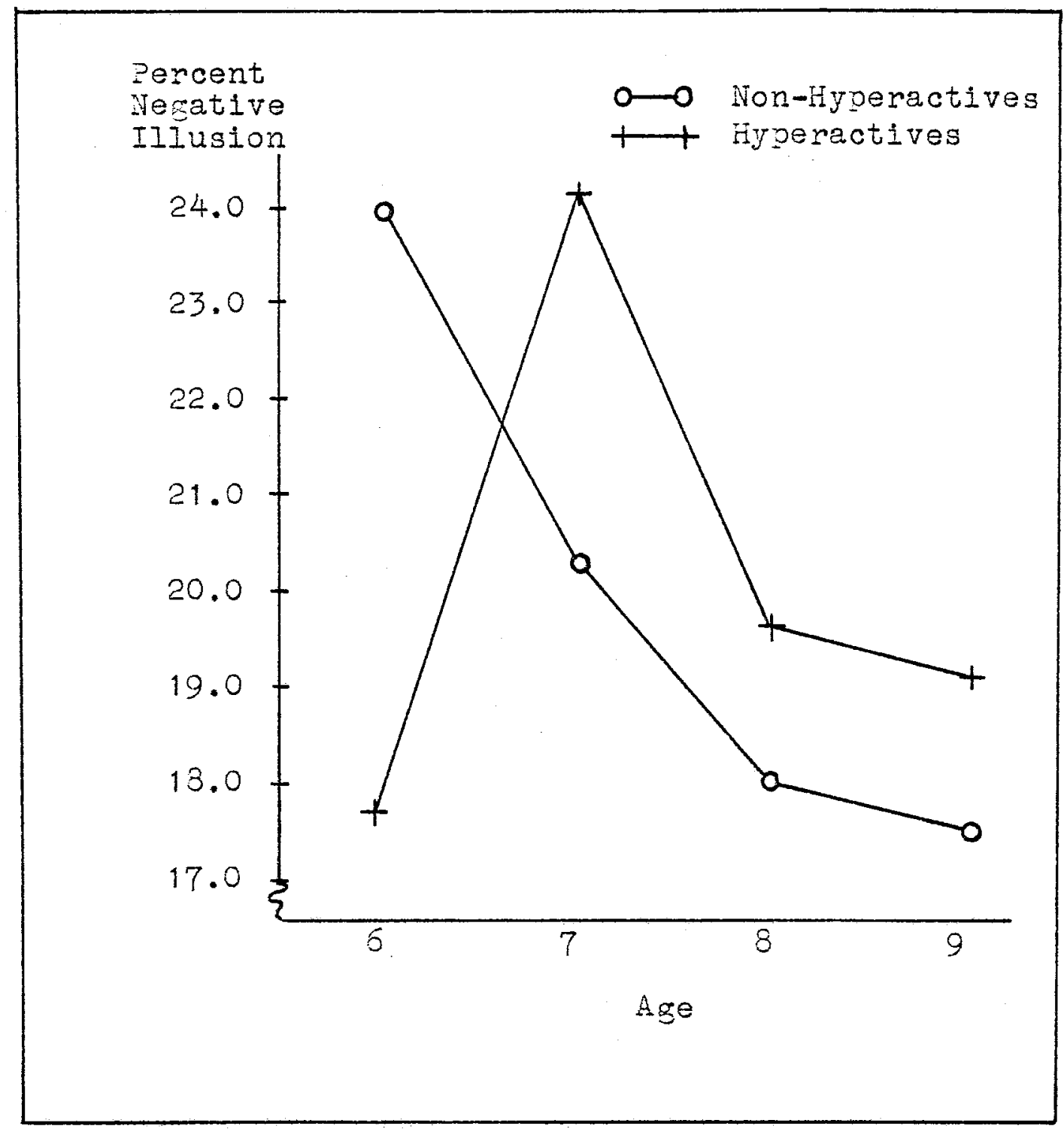

Fisure 7. Eercent illusion as a function of population by age. 
Table 4

Newman-Keuls Comparisons between Illusion for Non-iyperactives by Age

\begin{tabular}{|c|c|c|c|c|c|}
\hline \multirow[t]{2}{*}{ Age } & \multicolumn{2}{|r|}{9} & 8 & 7 & 6 \\
\hline & Mean ${ }^{a}$ & -120.23 & -123.58 & -138.54 & -163.20 \\
\hline 9 & -120.23 & - & 3.35 & 18.31 & $42.97^{\frac{*}{*}}$ \\
\hline 8 & -123.58 & & - & 14.96 & $39.62^{\text {i6 }}$ \\
\hline 7 & $-138 \cdot 54$ & & & - & 24.66 \\
\hline 6 & -163.20 & & & & - \\
\hline
\end{tabular}

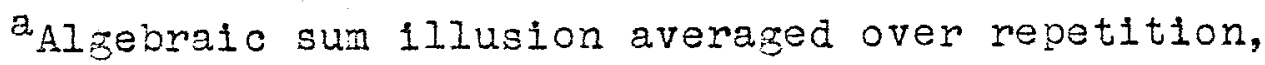
direction, and subjects.

$2<.05$ 
Table 5

Tests for Age Trend for the Non-Hyperactives Averazed over Direction, Repetition, and Subjects

\begin{tabular}{lrrrr}
\hline Source & SS & df & MS & $\underline{E}$ \\
\hline Linear & 124171.34 & 1 & 124171.34 & $9.467^{*}$ \\
Quadratic & 13621.35 & 1 & 13621.35 & 1.038 \\
Cubic & 21.85 & 1 & 21.85 & .002 \\
Subjects (PA) & 1154254. & 88 & 13116.52 & \\
\hline$*_{2}<.005$ & & & &
\end{tabular}

Table 6

Tests for Age Trend for the Hyperactives Averaged over Direction, Repetition, and Subjects

\begin{tabular}{lrrrr}
\hline Source & SS & df & MS & $\underline{\underline{\text { MS }}}$ \\
\hline Linear & 3.60 & 1 & 3.60 & .0003 \\
Quadratic & 67996.59 & 1 & 67996.59 & $5.1840^{*}$ \\
Cubic & 65720.20 & 1 & 55720.20 & $5.1015^{*}$ \\
Subjects (PA) & 1154254. & 88 & 13116.52 & \\
\hline$*^{*}<.01$ & & & &
\end{tabular}




\section{DISCUSSION}

Beflection-Impulsivity

The relationship postulated by ragan et al. (1964) between the tendency to reflect (predictor varlable) and perceptual recosnition errors (criterion variable) recelved further confirmation on the matching familiar fizures test. The correlation in this study between response time and error on the same perceptual recoznition task confirmed those of Kagan (1966) who found a median $\underline{\underline{r}}$ of about -.50 . However, the reported dramatic increase in response time with age for American children (Kagan \& Mogan, 1970) was not apparent here.

The present analysis led to the conclusion that hyperactives and non-hyperactives did not differ in tendency to reflect. The greater majority of the hyperactives, 42 out of 48, were receiving drug therapy. Of the 42 on medication, 33 were receiving methyl phenidate (Ritalin). A previous stuay by Campbell et al. (1971) of the erfects of methyl phenidate on cosnitive styles, utilizing the matching familiar flgures test as one index, found that hyperactive children under methylphenidate treatment were more reflective than hyperactives under placebo treatment. In addition, they found that unmedicated hyperactives were more impulsive than matched non-hyperactives. The comparative lack of impulsivity for hyperactives in the present study did not contradict the value of drug therapy, but could not 
speak for its merits, since pre and post treatment tests of the reflection dimension were not run.

That response time on the matchins famiziar figures test did not significantly correlate with magnitude of illusion was not surprising. The perceptual activity producing the illusion with the Muller-iyer is complex. Papid response time could mean a paucity of exploratory activity which would restrict the illusion. Insufflcient perceptual "encounters" would preclude assimilation of the component parts of the figure. Rapid response time could also mean a lack of exploratory activity which would increase the illusion. Insufficient "coupling" for coordination of the "encounters", perceptual error II, would lead to a less veridical estimation of line lengths. Magnitude of illusion is not directly related to response time theoretically and can not be explained simply as perceptual recognition error. That number of recosnition errors on the matching familiar figures test did not sisnificantly correlate with magnitude of illusion lends further support to this reasoning.

Some evidence that hyperactives recelving drug therapy would differ from non-hyperactives in magnitude of illusion can be gleaned from the Campbell et aI. (1971) findings. On the pretest, the unmedicated hyperactives isolated fewer Il gures on the Children's Imbedded Fizures Test (CDFT) than the nomal controls. In addition, on the posttest, the hyperactives receiving methylphenidate treatment did not 
locate significantly more embedded fizures than the hyperactives recelving the placebo. The conclusion was that scores on the CEPT did not change sienificantly with drug administration. The postulated relationship here is that the perceptual mechanisms necessary to break a figure down into its component parts on the CEIT are related to the perceptual mechanisms necessary to construct the illusion. Mannitude of Illusion

Over the age range of non-hyperactive boys tested, the documented decrease of illusion with the Nuller-Lyer as a function of ase (Plaget, 1969; Pollack, 1963, 1964; Wohlwill, 1960) found support. In this study, elght and nine year old non-hyperactives each showed less illusion than six year old non-hyperactives. Through a Piagetian explanation, perceptual exploration of the figure by the six year old non-hyperactive boys, the age which produced peak illusion for the non-hyperactives, involved sufficient perceptual encounters to structure the fisure and to produce the fleld effects that yield the illusion. By implication, representational schemes were present to allow assimilation of the figure. For the eight and nine year old nonhyperactives, the exploratory continuum eventuated in sufficient perceptual activity to reduce the illusion. Inspection of Figure 7 shows a unfform decreage as a function of age which supports the classification of the Muller-Lyer as a primary illusion. A significant linear age trend for the non-hyperactives confirmed this support. 
By way of a Piagetian explanation, the perceptual exploration of the figure by the six year old hyperactive boys in contrast to the six year old non-hyperactive boys involved fewer perceptual encounters, providing less structure to the figure and engendering weaker field effects, and/or involved less adequate representational schemes which permit assimilation of the figure. Because the illusion for the six year old hyperactives was less than the illusion for the seven year old hyperactives, the ase which produced peak illuston for the hyperactives, the decreased illusion for the six year old hyperactives indirectly substantiated the predicted curve of increasingly weaker illusion for nomal populations younger than five years of aze (Piaget, 1969). The significantly greater magnitude of illusion attained by the seven year old hyperactives was much like the performance of the six year old non-hyperactives. The perceptual exploration of the figure by the seven year old hyperactives, like the six year old non-nyperactives, included sufficient perceptual encounters, which structure the figure and promote field effects, to yield maximum iliusion. Assimilation of the figure via representational schemes occurred. However, the perceptual exploration of the figure by the seven year old hyperactives compared with the exploration by the seven year old non-hyperactives lacked the perceptual activity necessary to reduce the fleld effects that promote the illusion. By eight and nine years of age, the 
hyperactives, while demonstratins some greater illusion to the flgure, were not demonstrating signiflcantly greater illusion than their non-hyperactive are-mates. In other words, theis perceptual activity further along the exploratory continuum did not differ in effective reduction of the illuston.

The significant quadratic and cubic age trends, which describe the developmental trend for the hyperactives within the age range examined, resembled Plaget's idealized developmental curve for primary lllusion moved forward in years. Aberrant perceptual developinent for the hyperactives was not apparent. An estimation of developmental lag in years for the six year old hyperactives was difficult to ascertain because of the lack of data on normal children younger than flve years of age. But, developmental lag appeared to be maximum for the six year old hyperactives. Because empirical comparison indicated less illusion in $\mathrm{g} 1 \mathrm{x}$ year old hyperactives than in six year old non-hyperactives in this study and becauge empirtcal comparison indicated less illusion in six year old hyperactives than in five jear old children reported by Noelting, presumably nonhyperactive for the rost part, developmental las for the six year old hyperactives was at least greater than a year. Comparison between the empirtcal evidence obtained from the six year old hyperactives and Plaget's theoretical expectations of develoomental trend for normal populations younger than five years supported a lag in normal 
perceptual development. This conclusion is only theoretically supported for the six year old hyperactives because empirical comparison with non-hyperactives younger than five years is not possible.

Developmental lag appeared to be about a year for the seven year old hyperactives and insignificant for the eight and nine year old hyperactives. This conclusion of a las in normal perceptual development is empirically supported because empirical comparisons between seven, eicht, and nine year old hyperactives and six, seven, eight, and nine year old non-hyperactives are possible in this study. The seven year old hyperactives and the six year old non-hyperactives attained similar magnitudes of illusion. However, the upper end of the developmental age curve for the hyperactives was apparently steep because significant differences in illusion did not exist between the eight and nine year old hyperactives and their nonhyperactive counterparts in age.

An obvious suggestion for further research is to extend the data on normal children younger than five years and on hyperactive children younger than six years and older than ine years to further define the developmental curves for the two populations. Comparison data on unmedicated hyperactives, while difficult to obtain, would provide a base to judge the value of different drug therapies in terms of the complex perceptual mechanisms involved. The diagnostic use of susceptibility to illusion 
is difficult to foresee for evaluation of the individual. Wide between and vithin subject variability, especially with younger children in such perceptual tasks (Wohlwill, 1960 , p. 250), and a litrely curvilinear trend render this use difficult.

Perceptual exploration of the Muller-Lyer flgure is necessary to "construct" the illusion as well as reduce it. The developmental findinzs for six and seven year old hyperactives were in line with Browning's (1967) post-hoc hypothesis of hypo-responsiveness. Insufficient perceptual exploration in Piasetian terms could be translated as emitting "rewer and less varied responses per time interval per stimulus situation" (Browninz, 1967, o. 251). "Fewer responses" could be interpreted as reduced perceptual encounters and "less varied regponses" as inadequate perceptual activity. The six year old hyperactives emitted fewer responses than the six year old non-hyperactives and the seven year old hyperactives emitted less varied responses than the seven year old non-nyperactives.

The most surprising finding in this study was the mutually opposing effects between the two directions of adjustrnent seen in the highly siznifleant repetition $x$ direction interaction. Decrease of illusion with repetition, averaged over population, age, and direction was virtually nonexistent because of the interaction with direction shown in Figure 6. Empirical evidence demonstratins any parallel to Noelting's finding of spontaneous 
reduction of illusion with prosessive repetition could only be found in the data pertainins to progressive repetition with adjustment outwards. Comparisons with

Noelting's findings are somewhat tenuous because of the confounding influence of adjustment inwards in this study. However, illusion here was reduced in the second and again in the fifth block of repetitions with adjustment outwards. Confirmation of Noelting's finding of increasing reduction of illusion with increasing age was not apparent. With adjustrent outvards, in adition, the hyperactives and nonhyperactives did not differ in the application of perceptual activity which is necessary to reduce the field effects With progresive repetition. This implies, given the level of perceptual development, that the hyperactives compared with the non-hyperactives did not move at a slower pace through the exploratory continuum within the bounds of the progressive repetition in this study. It also implies, in a setting which permits progressive repetition as in this study, a las or aberrancy in normal perceptual development Por hyperactives was counter-indicated. That a hypothesis of a delay in the temporal maximum for hyperactives was not testable because support for a population $x$ repetition interaction was lacking is further evidence that the hyperactives and non-hyperactives did not differ in pace through the exoloratory continuum.

A precedent for an increase in illusion with adjustment inwards, resistant to a decrement with prosressive 
repetition, was not found in the literature. A number of possible confounding influences made interoretation of this finding difficult in terms of definitive perceptual mechanisms. The weaker illusion for adjustment inwards may have occurred because of a startins position efrect in that the averase adjusted distance for direction inwards was sreater than the average adjusted distance for direction outwards. Starting positions were equidistant from the POE, not the average PSE. Illusion may have increased for adjustment inwards with progressive repetition in an attempt to resolve an apparent conflict between adjusted positions for each direction. It appears that the adjusted component was initially overestimated for direction outwards, engendering greater negative illusion, and initially underestimated in direction inwards, engendering lesser negative illusion. With each adjustment repetition outwards, and with each of a series of partial adjustments within an adjustment repetition, a lonser line temporally succeeds a shorter line and the reverse for each adjustment repetition invards. Some tendency to less illusion overall for both adjustment directions in the fifth block of repetitions, while non-significant for adjustment inwards, subgests the value of extending the number of repetitions in further research. At best, it can be said that whatever influences were abroad, population and age did not differ in magnitude of illusion with adjustment inwards. A precedent for differential illusion between 
adjustment invards and adjustnent outwards with four repetitions in an $A B B A$ order was found in a study by Jenkin and Vest (1959) of organic mental defectives. Organic children tended to demonstrate remariably weaker illusion with adjustment inwards when compared with normal children. Direction of adjustment was included as an independent variable in this study by reason that Jenkin and West suscested further work on this variable for diagnostic purposes. Relevance here was based on the commonly made comparisons between the behavioral correlates of known brain-damaged children and of hyperactive children. It is important to note, then, the effects of airection of adjustment, inwards or outwards, did not differ here for the hyperactives and non-hyperactives. 
Brownins, R. iv. Hypo-responsiveness as a benavioral correlate of orain-damage in children. Psychological Reports, 1967, 20, 251-259.

Campbell, S. B., Douslas, V. I., \& Morgenstern, G. Coznitive styles in hyperactive children and the effect of methylphenidate. Journal of Child Psycholosy and Psychiatry, 1971, 12, 55-67.

Douglas, V. I. Stop, look and listen: The problem of sustained attention and impulse control in hyperactive and normal children. Canadian Journal of Behavioural Sclence, 1972, $4(4), 259-282$.

Easterbrook, J.A. The effect of emotion on cue utilization and the orsanization of behavior. Psycholozical Review, $1959,66,183-201$.

Flavell, J. H. The developmental psychology of Jean Piaget. Princeton, New Jersey: Van Nostrand, 1963.

Freiberss, V., \& Douglas, V. I. Concept learning in hyperactive and normal children. Journal of Abnormal Psychology, 1969, 74, 388-395.

Jenkin, N., \& West, N. I. Perception in organic mental defectives: An exploratory study: II. The MuelierLyer illusion. Training School Bulletin, Vineland, $1959,55,67-70$.

Kazan, J. Developmental studies in reflection and analysis. In A. H. Kidd \& J. H. Rivoire (Eds.), Perceptual development in children. New York: International Universities Press, 1966.

Kagan, J., \& Kogan, N. Individual variation in cognitive processes. In P. H. Mussen (Ed.), Carmichael's Manual of Child Psycholozy (Vol. 1, 3rd ed.). New York: John Wiley, 1970.

Kagan, J., Rosman, B., Day, D., Albert, J., \& Phill1ps, W. Information processing in the child: Significance of analytic and reflective attitudes. Psychological Monocraphs, 1964, 78, (1, Whole No. 573).

Kiris, R. E. Experimental desizn: Procedures for the behavioral sciences. Belmont, Californla: Wadsworth, 1968. 
Millichap, J.G. The hyperactive child with minimal brain disfunction. Ch1cazo: Year Book Medical Publishers, 1975.

Piaret, J. The mechanisms of perception (G. N. Seasrim, trans.). New York: Bas1c Books, 1969. (Originally published, 1961).

Pollack, R. H. Contour detectibility threshold as a function of chronological age. Perceptual and Motor Ski11s, 1963, 17, 411-417.

Pollack, R. H. Simultaneous and successive presentation of elements of the Muller-Lyer figure and chronolozical age. Perceptual and Motor Skills, 1964, 19, 303-310.

Ross, A. O. Psychological aspects of learning disabilities and readins disorders. New York: NoGraw-Hill, 1976.

Tarver, S. G., \& Hallahan, D. P. Attention deflcits in children with learning disabilities: A review. Journal of Learning Disabilities, 1974, I(9), 560-569.

Wohlwill, J. Developmental studies of perception. Bsycholoxical Bulletin, 1960, 57(4), 249-288. 


\section{APPENDICES}


APPENDIX A: PHYSICIAN AND MPDICATION INFORMATION FOR THZ FYPERACTIVES

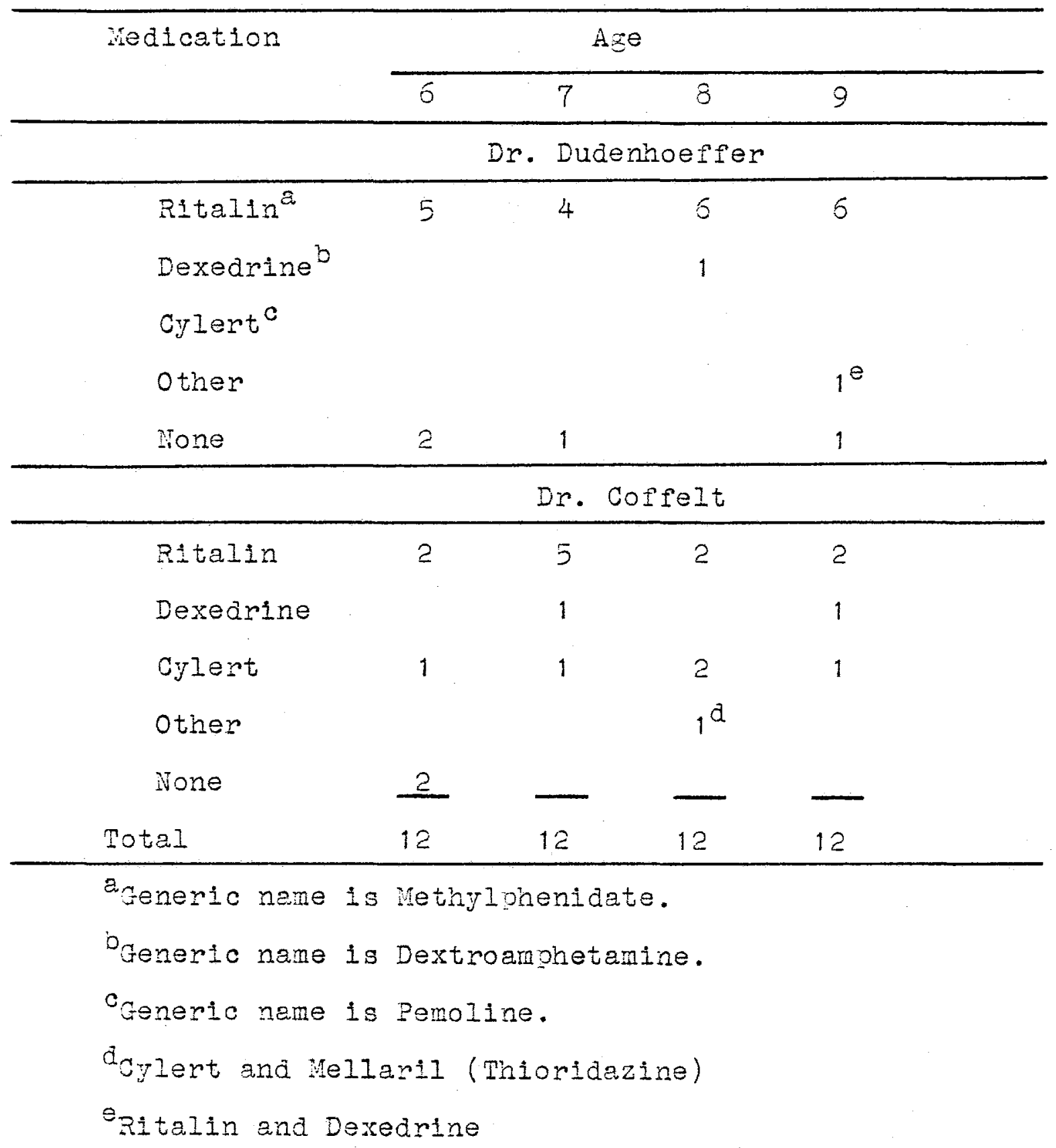


APPENDIX 3: SAYELE ITER FROM MATCHING FANILIAR FIGURES TEST BY JEROME KAGAN
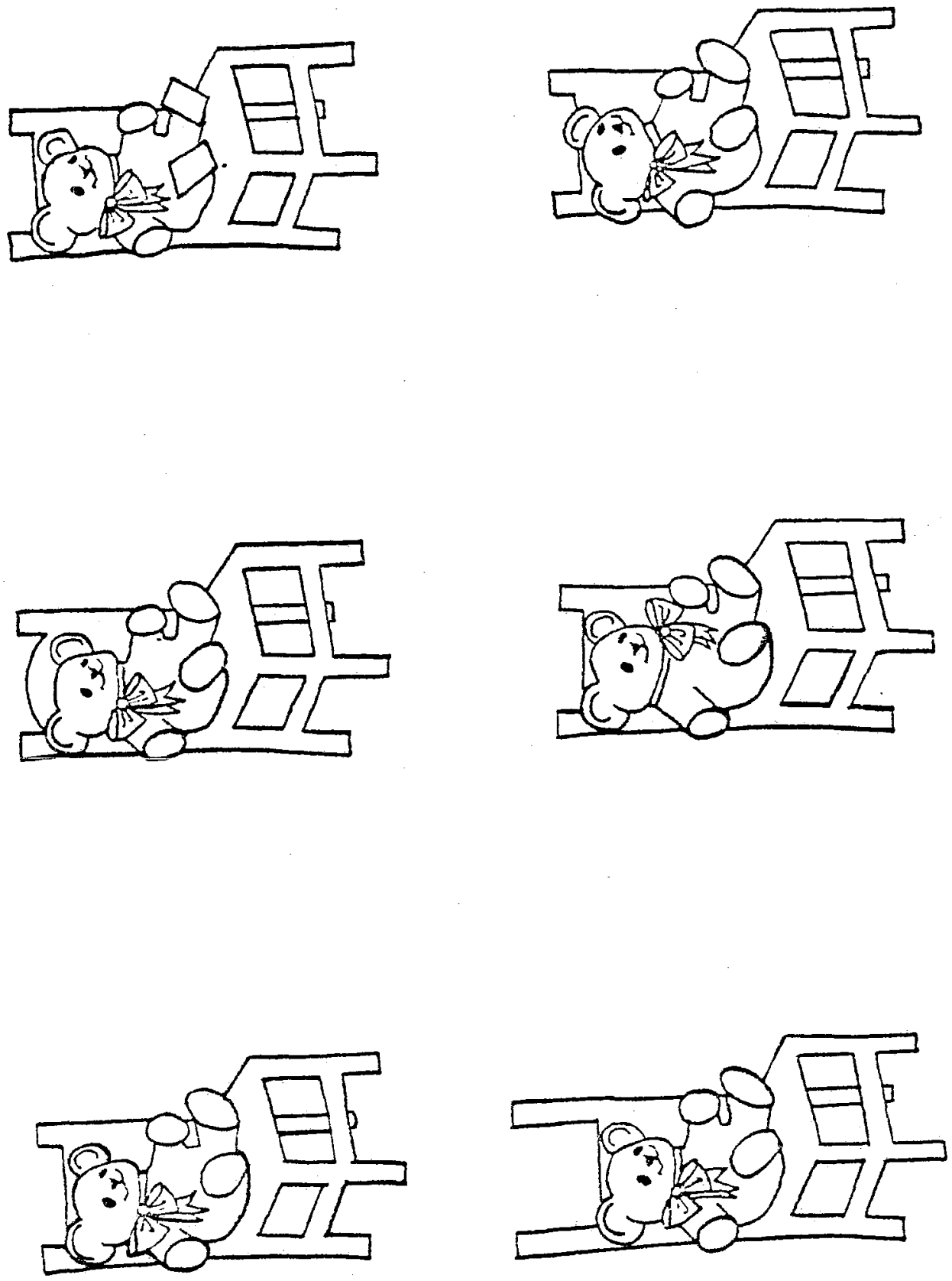
APPENDIX C: DIRECTIONS FOR MATCHING FAMILIAR FIGURES TEST

The following is from the unpublished matching familLar fligures test by Jerome Kagan and is obtainable from the author at Harvard University, Cambridge, Massachusetts:

"I am goins to show you a picture of something you know and then some pictures that look like it. You will have to point to the picture on this bottom page (point) that is just like the one on this top page (point). Let's do some For practice." I shows practice items and helps the cilid to find the correct angwer. "Now we are going to do some that are a little bit harder. You will see a picture on top and six pictures on the bottom. Find the one that is just like the one on top and point to it."

I will record latency to first response to the hali-second, total number of errors for each item and the order in which the errors are made. If $S$ is correct, $\mathbb{E}$ will praise. If Wrong, I will say, "No, that is not the right one. Find the one that is just like this one (point)." Continue to code responses (not times) until child makes a maximum or six exrors or gets the item correct. I incorrect, $E$ Will show the richt answer.

It is necessary to have a stand to place the test booklet on so that both the stimulus and the alternatives are clearly visible to the $\mathrm{S}$ at the same time. The two pages should be practically at right angles to one another. Note: It is desirable to enclose each page in clear plastic in order to zeep paces clean. 
APPENDIX D: INSTRUCTIONS FOR THE MULLIR-LYAR FIGURE

The adjustable arm was placed in one of the two appropriate starting positions (begin with direction outwards or direction inwards) before the subject entered.

Here is a line (pointing with a pencil to the stationary closed conponent) that begins here and ends there. The itne has arrows on the end (pointing). Over here is a line (pointing to the movable open component) that begins here and ends there. This line has forks on the end. I would like you to move the arm to the place where the lines are the same length, that 1s, just as long as each other.

After several adjustments the subject was told, "I would like you to do this several more times". The subjects were asked to not use their ingers to meesure. When a subject asked if he was right or wrong, he was told there was no "right" or "wrong" with this task. The point was made that the experimenter wanted to find out how the subject "saw" the Iines. 